\title{
The oxidation and surface speciation of indium and indium oxides exposed to atmospheric oxidants.
}

\author{
Zachary M. Detweiler ${ }^{\dagger}$, Steven M. Wulfsberg ${ }^{\dagger}$, Matthew G. Frith, Andrew B. Bocarsly, \\ and Steven L. Bernasek* \\ Department of Chemistry, Princeton University, Princeton, NJ 08544 USA
}

\begin{abstract}
Metallic Indium and its oxides are useful in electronics applications in transparent conducting electrodes, as well as in electrocatalytic applications. In order to understand more fully the speciation of the indium and oxygen composition of the indium surface exposed to atmospheric oxidants, XPS, HREELS, and TPD were used to study the indium surface exposed to water, oxygen, and carbon dioxide. Clean In and authentic samples of $\operatorname{In}_{2} \mathrm{O}_{3}$ and $\mathrm{In}(\mathrm{OH})_{3}$ were examined with XPS to provide standard spectra. Indium was exposed to $\mathrm{O}_{2}$ and $\mathrm{H}_{2} \mathrm{O}$, and the ratio of $\mathrm{O}^{2-}$ to $\mathrm{OH}^{-}$in the $\mathrm{O} 1 \mathrm{~s}$ XPS region was used to monitor oxidation and speciation of the surface. HREELS and TPD indicate that water dissociates on the indium surface even at low temperature, and that $\operatorname{In}_{2} \mathrm{O}_{3}$ forms at higher temperatures. Initially, $\mathrm{OH}-$ is the major species at the surface. Pure $\mathrm{In}_{2} \mathrm{O}_{3}$ is also $\mathrm{OH}$ - terminated following water exposure. Ambient pressure XPS studies of water exposure to these surfaces suggest that high water pressures tend to passivate the surface, inhibiting extensive oxide formation.

$\dagger$ These authors contributed equally to the work described here.

* Corresponding author
\end{abstract}




\section{Introduction}

Indium in its pure elemental form is used in a few applications, such as a gasket seal in vacuum systems, as a heat conductor in electronic cooling and cryogenic applications, and as a reducing agent in chemical reactions. ${ }^{1-3}$ More commonly, indium is either alloyed with other metals to modify their properties (for instance, as a component in eutectics like gallium-indium, gallium-indium-tin, and bismuth-indium-tin), combined with group V elements to make III-V semiconductors, or employed as a transparent conductor as indium oxide or, most often, indium tin oxide (ITO). ${ }^{1}$ In spite of these important uses, the ambient corrosion of indium metal and its oxides are not as well documented as more abundant and more widely used structural metals.

Due to its wide use in electronics, ITO, unlike $\operatorname{In}^{0}$ and $\operatorname{In}_{2} \mathrm{O}_{3}$, has been characterized extensively using UHV techniques, but the attribution of oxide and hydroxide species (which are extremely important for performance and reproducibility) to Sn or In in ITO species is difficult and often ambiguous. ${ }^{4}$ The work function of ITO can be altered by the method and parameters of preparation and a major contributor to this variation in properties is likely humidity. ${ }^{5} \mathrm{SnO}_{2}$ nanoparticles have even been used as humidity sensors, showing significant conductivity perturbation in the presence of varying water vapor pressure. ${ }^{7}$ Little attention has been placed on the role of $\operatorname{In}_{2} \mathrm{O}_{3}$-water interactions and essentially no studies have been done to discern the impact of atmospheric water on the speciation at the indium solid-gas interface. Elucidating the behavior of water at the gas-solid interface of indium is critical for future applications of indium metal and indium oxide, in addition to various indium containing mixed metal compounds. To determine the role of the indium oxidation state in aqueous electrochemical $\mathrm{CO}_{2}$ 
reduction to formate, a deeper understanding of the interfacial speciation at the electrode surface was necessary. Recently the role of these specific oxides has been implicated in electrocatalytic $\mathrm{CO}_{2}$ reduction at the oxidized indium electrode. ${ }^{8}$

The study of metal and metal oxide interactions with small molecules is a welldeveloped field with many tools and techniques available. The study of oxygen and water corrosion of various structural metals is extensive, as is the case with the corrosion of iron, for example. ${ }^{9,10}$ Some corrosion studies of indium metal have previously been performed. Lin et. al. studied indium metal and indium (III) oxide using x-ray photoelectron spectroscopy (XPS) and Auger electron spectroscopy (AES). ${ }^{11}$ Rossnagel et. al. employed AES to monitor the oxidation of $\mathrm{In}^{0}$ with $\mathrm{O}_{2}, \mathrm{H}_{2} \mathrm{O}, \mathrm{CO}$, and $\mathrm{CO}_{2}$, finding that an In oxide layer developed on exposure to all of the oxygen containing species, but in the case of $\mathrm{CO}$ and $\mathrm{CO}_{2}$, oxidation may have been due to trace $\mathrm{O}_{2}$ and $\mathrm{H}_{2} \mathrm{O}$ contamination. ${ }^{12}$ The oxidation of polycrystalline $\mathrm{In}^{0}$ with $\mathrm{O}_{2}$ was investigated with XPS and secondary ion mass spectrometry (SIMS) by Hewitt et. al., who observed that $\mathrm{O}_{2}$ continues to oxidize $\mathrm{In}^{0}$ after thousands of Langmuirs ( $\mathrm{L}$ ) of $\mathrm{O}_{2}$ exposure, forming an $\mathrm{In}_{2} \mathrm{O}_{3}$ film. ${ }^{13}$ Concurrently, Sen et. al. showed the formation of an $\operatorname{In}_{2} \mathrm{O}_{3}$ film on $\mathrm{O}_{2}$ exposure to $\operatorname{In}^{0}$, using AES. They noted the loss of $\operatorname{In}^{0}$ signal after $10^{6} \mathrm{~L}$ of $\mathrm{O}_{2}$ exposure. ${ }^{14}$ More recently, Jeong et. al. studied the conductivity of indium oxide thin films as a function of deposition parameters including substrate temperature, deposition rate, and oxygen partial pressure, among others, and demonstrated the importance of the $\mathrm{In} / \mathrm{O}$ ratio for the conductivity of the oxide film. ${ }^{15}$

It is important to note that these experiments on the detailed origin of oxygen and indium species were performed on UHV prepared samples, which qualitatively 
demonstrate significant differences from indium oxide species that are present after exposure to atmospheric conditions. Most notably, the identification of the high binding energy O 1s species observed in XPS measurements in all these experiments is conflicting. Here we attempt to address this shortcoming in the literature through a series of XPS, high-resolution electron energy loss spectroscopy (HREELS) and temperature programmed desorption (TPD) experiments. The explicit interactions of water with $\operatorname{In}^{0}$ and $\mathrm{In}_{2} \mathrm{O}_{3}$ have not been characterized in terms of adsorption and dissociation, and the actual species formed at the solid-gas interface upon adsorption have been addressed only sparingly. Due to the lack of adequate information about these interactions and the role that indium speciation can play in the electronic properties of indium containing materials, the oxidation of indium upon exposure to $\mathrm{H}_{2} \mathrm{O}, \mathrm{O}_{2}$, and $\mathrm{CO}_{2}$ was systematically probed here.

\section{Experimental}

In order to probe the fundamental interactions of small molecule oxidants with the most common oxidation states of indium (metallic and trivalent), experiments were performed under both UHV and ambient pressure conditions. First, standards were measured as points of reference for the subsequent exposure studies.

\section{Standard Indium Sample Analysis}

XPS control and dosing studies were performed using a VG Scientific Mk II ESCALab with a magnesium x-ray source and hemispherical electron analyzer set at 20 $\mathrm{eV}$ pass energy. Spectra were calibrated to the adventitious $\mathrm{C} 1 \mathrm{~s}$ peak at $285 \mathrm{eV}$, or, when absent, the $\mathrm{O} 1 \mathrm{~s}$ peak at $530 \mathrm{eV}$ binding energy. Indium metal shot (Alfa Aesar 99.99\% metals basis) was pounded into a flat circle of $\sim 1.5 \mathrm{~cm}$ diameter and $\sim 0.3 \mathrm{~mm}$ 
thickness and allowed to oxidize in atmosphere overnight before being introduced into vacuum. Powder samples of $\operatorname{In}_{2} \mathrm{O}_{3}$ (Aldrich $99.99 \%$ metals basis) and $\mathrm{In}(\mathrm{OH})_{3}$ (Aldrich 99.99\% metals basis) were liberally pressed onto carbon tape and introduced into vacuum as received. Clean metallic indium spectra were obtained by sputtering the native oxide sample with a differentially pumped $\mathrm{Ar}^{+}$beam at $2 \mathrm{keV}$ and $10 \mathrm{~mA}$ emission current, delivering 4-6 $\mu \mathrm{A}$ to the sample for 1 hour.

All XPS spectra were deconvoluted using CasaXPS peak fitting software with Shirley background subtractions and Gaussian-Lorentzian peak distributions.

\section{Adsorption experiments studied via XPS}

After obtaining the reference speciation peak information from standard samples, the progress of oxidation as a function of oxidant exposure was observed. $\mathrm{H}_{2} \mathrm{O}, \mathrm{O}_{2}$, and $\mathrm{CO}_{2}$ dosing experiments were performed on an $\mathrm{Ar}^{+}$sputtered indium metal substrate in the ESCAlab described above. The substrate was exposed by controllably leaking in the

respective oxidants from between $0.5 \mathrm{~L}$ and $10^{5} \mathrm{~L}$ at pressures from $10^{-9}$ to $10^{-5}$ Torr and recording In 3d, In Auger, O 1s, C 1s and survey XPS and Auger spectra after each exposure.

Ultra-high purity $\mathrm{O}_{2}$ and $\mathrm{CO}_{2}$ were obtained from AirGas Inc. and leaked into the chamber through a mechanically pumped manifold via a bakeable sapphire sealed leak valve. $\mathrm{H}_{2} \mathrm{O}$ was obtained from a Millipore MilliQ system with a resistance of 18.2 $\mathrm{M} \Omega / \mathrm{cm}$ and placed in a glass bulb attached to the manifold and degassed by directly pumping on the volume of water. Gas doses were monitored with a Stanford Research Systems RGA-200 residual gas analyzer with a channeltron electron multiplier. 
Speciation at high $\mathrm{H}_{2} \mathrm{O}$ pressures studied by AP-XPS experiments at $A L S$

In order to help extrapolate the UHV information to atmospheric conditions, higher pressure experiments were performed using an ambient pressure XPS (AP-XPS) system to dose metallic and oxidized indium species with water. AP-XPS measurements were obtained at the Advanced Light Source at LBNL beamline 9.3.2. An In ${ }^{0}$ sample was prepared from metallic indium shot, then $\mathrm{Ar}^{+}$sputtered at $2 \mathrm{keV}$ and $\sim 6 \mu \mathrm{A}$ for 1.5 hours, and an $\operatorname{In}_{2} \mathrm{O}_{3}$ sample was prepared by drop-casting isopropanol suspended powder onto a 1 micron film of $\mathrm{Au}$ on a $1 \mathrm{~cm}^{2} \mathrm{Si}$ wafer and then baking at $250{ }^{\circ} \mathrm{C}$ for 1 hour. Ultrahigh purity $\mathrm{CO}_{2}$ (AirGas) and water from a Millipore MilliQ water system at 18.2 $\mathrm{M} \Omega / \mathrm{cm}$ was used after evacuating atmospheric gases with a mechanical pump. Gas pressures were monitored with a Stanford Research Systems RGA-100 residual gas analyzer in the electron analyzer chamber.

\section{HREELS and TPD chamber and preparation}

In an attempt to gather further information about the mechanism of indium oxidation and surface speciation distributions at oxidized indium surfaces, HREELS and TPD spectra were collected under UHV conditions from a flat, polycrystalline indium

sample treated as described below. A custom chamber with a base pressure of $1.2 \times 10^{-10}$ Torr was used to perform these HREELS and TPD measurements on an indium foil from Alfa Aesar (99.99\% metals basis) mounted to a custom tantalum foil stage capable of being resistively heated and liquid $\mathrm{N}_{2}$ cooled. The indium foil was brought to a mirror finish by pressing into a glass slide. An ELS 3000 HREELS system was used to obtain HREELS spectra and a Stanford Research Systems RGA-200 residual gas analyzer was used to record system pressure during TPD analysis. The sample was sputtered clean by 
backfilling the chamber with Ar to a pressure of $5 \times 10^{-6}$ Torr and sputtering at $2 \mathrm{keV}$ and $\sim 6 \mu \mathrm{A}$ for 1 hour at an $\mathrm{Ar}^{+}$beam incidence angle of $20^{\circ}$.

HREELS spectra were obtained at the specular angle with a beam energy of $5 \mathrm{eV}$ and direct transmission fwhm of $\sim 3 \mathrm{meV}$, and incident beam angle of $60^{\circ}$.

TPD was performed with the sample $35^{\circ}$ off normal from the RGA in an attempt to obtain a normalized desorption profile for various species. The stage was brought within 3 inches of the ionizing filament of the RGA. Programmed desorption was performed at a rate of $1 \mathrm{~K} / 6$ seconds.

\section{Results and Discussion}

\section{Authentic Control Samples}

XPS of $\mathrm{Ar}^{+}$sputtered indium metal shows that sputtering removes almost all detectable $\mathrm{O} 1 \mathrm{~s}$ and $\mathrm{C}$ 1s XPS signal after 1 hour at $2 \mathrm{keV}$ and $10 \mathrm{~mA}$ emission current. As seen in Figure 1a, as the metallic In $3 d_{5 / 2}$ peak at $443.7 \mathrm{eV}$ is exposed, a significant plasmon loss feature grows in at $11.7 \mathrm{eV}$ higher binding energy than its parent peak, in accordance with previous studies. ${ }^{11,13}$ In addition, the full width half $\max (\mathrm{fwhm})$ of the In $3 d_{5 / 2}$ and In $3 d_{3 / 2}$ peaks are considerably less than the fwhm of the In $3 d$ peaks of $\operatorname{In}_{2} \mathrm{O}_{3}$ (In $3 \mathrm{~d}_{5 / 2}$ at $\left.444.7 \mathrm{eV}\right)$ and $\mathrm{In}(\mathrm{OH})_{3}\left(\mathrm{In} 3 \mathrm{~d}_{5 / 2}\right.$ at $\left.445.1 \mathrm{eV}\right)$, as seen in Figure $1 \mathrm{~b}$ and Figure 1c, respectively. Even after sputtering at length, there is still a small $\mathrm{O}$ 1s signal from the indium substrate at $529.9 \mathrm{eV}$, which coincides with a small shoulder in the In $3 \mathrm{~d}$ region with an $\mathrm{In} 3 \mathrm{~d}_{5 / 2}$ peak at $444.8 \mathrm{eV}$. This $\mathrm{O} 1 \mathrm{~s}$ signal likely is due to residual oxygen contamination in the chamber, which reacts before spectra can be obtained, or is from oxide already present in the indium sample. 
As is common for the $\mathrm{O} 1 \mathrm{~s}$ region previously reported for bulk $\operatorname{In}_{2} \mathrm{O}_{3}$ samples, there are two significant peaks present at $530.4 \mathrm{eV}$ and $532.3 \mathrm{eV}$, generally attributed to bulk oxygen and surface adsorbed oxygen, respectively. ${ }^{11,13}$ However, this assignment makes little sense when the peaks are of equal size, as is the case here. More likely, the higher binding energy peak is actually a hydroxyl species. ${ }^{16,17}$ The only other features seen in the In $3 \mathrm{~d}$ region are due to $\mathrm{Ka}_{3}$ and $\mathrm{K} \alpha_{4}$ lines from the un-monochromated $\mathrm{x}$-ray source, observed as satellites of large peaks at $\sim 8.4 \mathrm{eV}$ lower binding energy in collected XPS spectra.

The $\mathrm{O} 1 \mathrm{~s}$ region of the $\operatorname{In}(\mathrm{OH})_{3}$ sample demonstrates oxygen species which are similarly spaced as the $\mathrm{In}_{2} \mathrm{O}_{3}$ species, but shifted to slightly lower binding energy $(529.3$ $\mathrm{eV}$ and $531.7 \mathrm{eV}$, respectively). The shift in the $\mathrm{In} 3 \mathrm{~d}_{5 / 2}$ peak to higher binding energy and shift in $\mathrm{O}$ 1s peaks to lower binding energy indicates that the In atom has lower electron density in $\operatorname{In}(\mathrm{OH})_{3}$ than in $\operatorname{In}_{2} \mathrm{O}_{3}$, which is normally the case for metal hydroxides compared to their equivalent oxidation state metal oxide.

It is important to note that although the oxidized indium species are not metallic, $\mathrm{In}_{2} \mathrm{O}_{3}$ has a band gap of $2.3 \mathrm{eV}$ and is commonly used with tin oxide as a transparent conducting film in electronics, and no significant charging was observed. $\operatorname{In}(\mathrm{OH})_{3}$ on the other hand, displayed significant charging (up to $5 \mathrm{eV}$ ) and emitted a visible blue glow under x-ray illumination, understood to originate from oxygen vacancies in the crystal structure of the hydroxide. ${ }^{18}$ 
In $3 d$

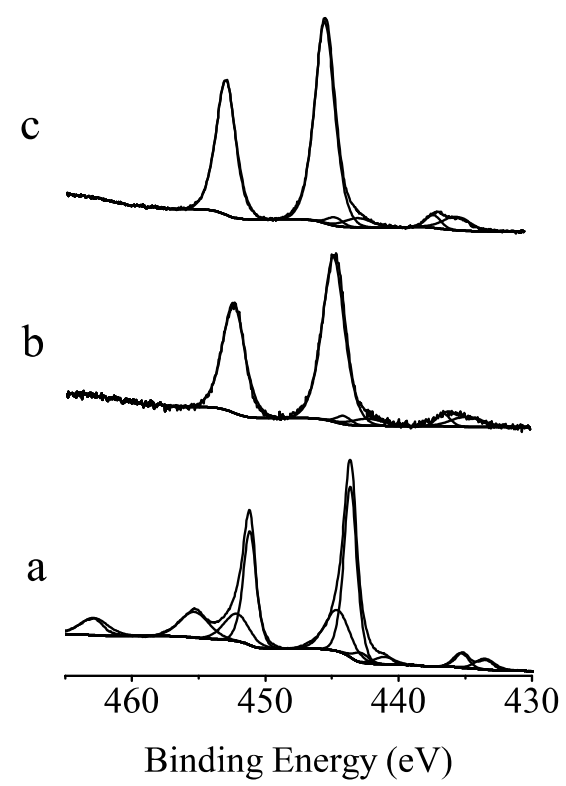

O 1s
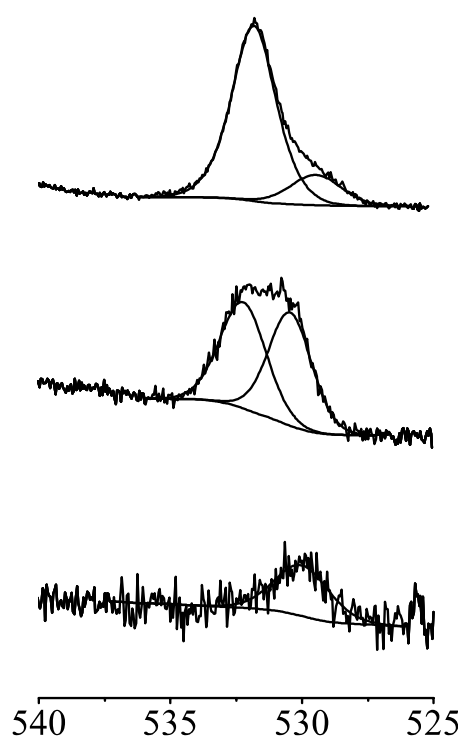

Binding Energy (eV)

Figure 1. XPS spectra of the In $3 d$ and $\mathrm{O}$ 1s regions of (a) sputtered In metal, (b) $\operatorname{In}_{2} \mathrm{O}_{3}$, and (c) $\operatorname{In}(\mathrm{OH})_{3}$.

\section{Oxidation of Indium with Gases $\left(\mathrm{O}_{2}, \mathrm{H}_{2} \mathrm{O}\right.$ and $\left.\mathrm{CO}_{2}\right)$ Monitored by XPS}

After collecting peak information from the authentic samples, it was possible to begin measuring the change of indium surfaces during exposure to the small molecule oxidants of interest. As mentioned above, the presence of two oxygen species in $\operatorname{In}_{2} \mathrm{O}_{3}$ has been previously noted, but the assignment of the species that generates the higher binding energy $\mathrm{O} 1 \mathrm{~s}$ peak at $\sim 532 \mathrm{eV}$ is not widely agreed upon, some assigning it to adsorbed oxygen and others attributing it to hydroxide. Those that attribute this $\mathrm{O} 1 \mathrm{~s}$ species to adsorbed oxygen do so because they have only exposed the indium to oxygen in UHV conditions in order to monitor oxide growth, so that any oxygen signal was assumed to originate from $\mathrm{O}_{2} \cdot{ }^{11,13}$ Those who attribute the higher binding energy peak to a hydroxyl species do so in analogy to what has previously been reported for oxygen 
speciation at other metal oxide interfaces. ${ }^{17,}{ }^{19}$ For this reason, the oxidation study performed by Rossnagel et. al. at indium metal with gaseous oxidants was repeated, but with a focus on the $\mathrm{O} 1 \mathrm{~s}$ speciation.

Figure $2 \mathrm{a}$ again shows the $\mathrm{Ar}^{+}$sputtered indium substrate, which is essentially oxide free, demonstrated by the flat $\mathrm{O} 1 \mathrm{~s}$ region. The $\mathrm{In} 3 \mathrm{~d}$ region shows that there is a dominant In $3 \mathrm{~d}_{5 / 2}$ peak at $443.7 \mathrm{eV}$ with a strong $11.7 \mathrm{eV}$ plasmon loss feature. The In LMM Auger region shows very sharp transitions, indicative of the metallic species, which is now dominant at the exposed interface. Figure $2 b$ shows the sputtered indium surface after it has been exposed to around $100,000 \mathrm{~L}$ of $\mathrm{O}_{2}$. The $\mathrm{O} 1 \mathrm{~s}$ region shows a large gain in $\mathrm{O}$ 1s signal, with a significant peak at $530 \mathrm{eV}$ and a small shoulder around $531.8 \mathrm{eV}$. The In $3 \mathrm{~d}$ region now distinctly shows two In $3 \mathrm{~d}_{5 / 2}$ species, the metallic species at 443.7 and an oxidized species at $444.8 \mathrm{eV}$ that matches closely with $\operatorname{In}_{2} \mathrm{O}_{3}$, but is not distinguishable, within the resolution of the spectrometer, from an $\operatorname{In}(\mathrm{OH})_{3} \operatorname{In} 3 \mathrm{~d}_{5 / 2}$ signal. After oxygen exposure the In Auger region has significantly different, broadened features, with residual sharp peaks from the metallic species. XPS after exposing an equal amount of $\mathrm{H}_{2} \mathrm{O}$ to the sputtered substrate is shown in Figure 2c. The $\mathrm{O} 1 \mathrm{~s}$ region demonstrates a significantly larger amount of the high binding energy oxygen species. In addition, the In $3 \mathrm{~d}$ region shows a smaller amount of oxidation, which is also seen in the Auger region, where the metallic peaks are more pronounced in the region between the two indium species. 


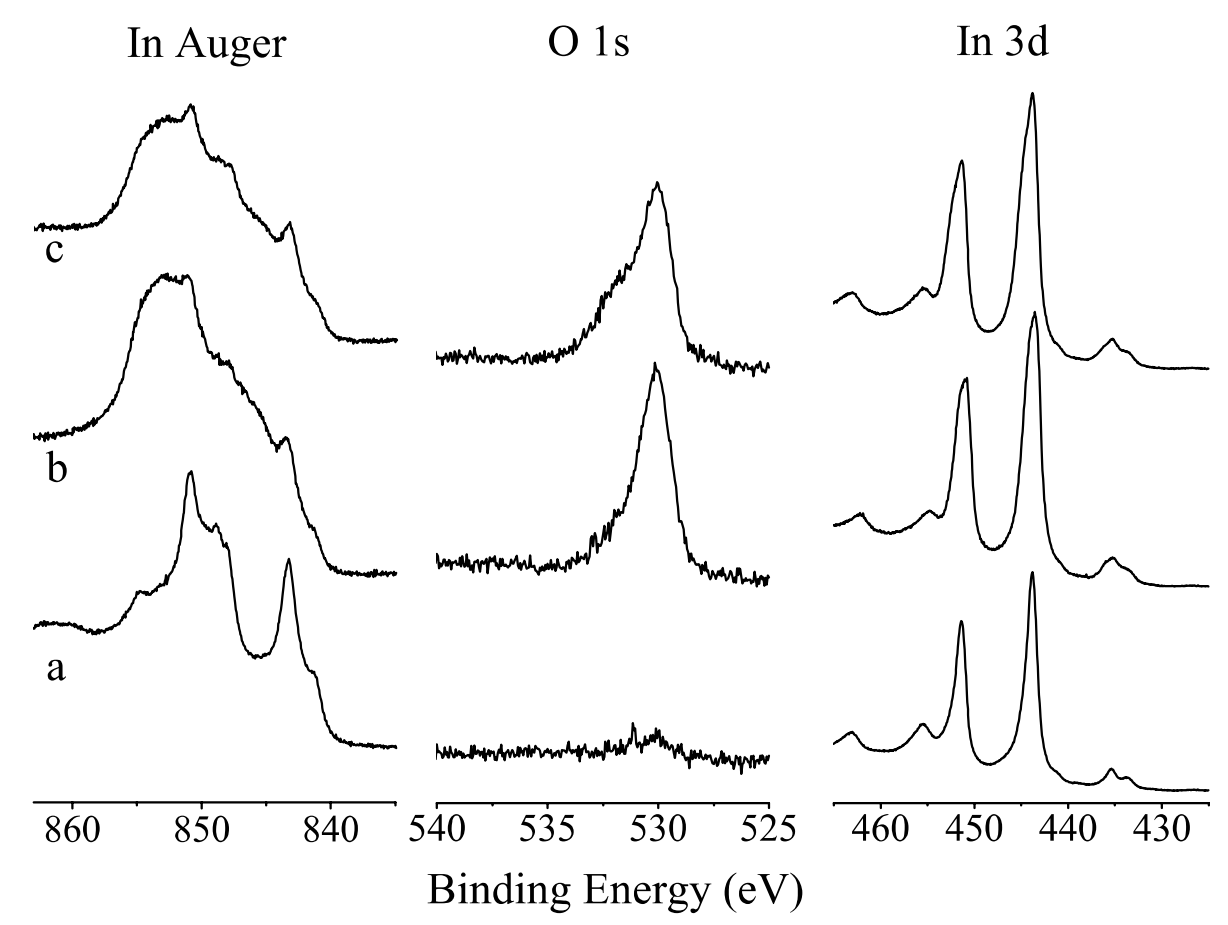

Figure 2. XPS spectra of (a) an $\mathrm{Ar}^{+}$sputtered indium foil that has subsequently been exposed to (b) $100,000 \mathrm{~L}$ of $\mathrm{O}_{2}$ or (c) $100,000 \mathrm{~L}$ of $\mathrm{H}_{2} \mathrm{O}$.

The oxidation of indium can be followed as a function of $\mathrm{O}_{2}$ or $\mathrm{H}_{2} \mathrm{O}$ exposure in order to determine sticking coefficients of the oxygen containing species and their oxidation rates of the bulk sample. Figure 3 shows the $\operatorname{In}^{3+} / \operatorname{In}^{0}$ ratio, determined by comparing the peak areas for the two In $3 \mathrm{~d}_{5 / 2}$ species at $444.8 \mathrm{eV}$ and $443.7 \mathrm{eV}$, respectively. It is important to note that even though the sputtering has managed to dramatically rid the surface of oxidized indium, there is still a reasonable amount of oxidized indium peak area that cannot be removed. The ratios for indium speciation demonstrate similar behavior to that seen by Rossnagel et. al., who reported the oxygen coverage as a function of $\mathrm{O}_{2}$ and $\mathrm{H}_{2} \mathrm{O}$ exposure. ${ }^{12}$ 
For clarity in the following discussions, the main peaks of interest are summarized in Table 1. The $\operatorname{In}^{3+}$ peak is attributed to a mixed oxide state, including both indium oxide and indium hydroxide species. These two species cannot be resolved in the In $3 \mathrm{~d}$ peak region with the photoelectron spectrometer used in this study. The $\mathrm{O} 1 \mathrm{~s}$ peaks however, can be strongly attributed to the oxide speciation present. These peak positions allow subsequent observations to be easily discussed and exposures will be presented in this context.

\begin{tabular}{r|cc|cc} 
& \multicolumn{2}{|c|}{$\mathrm{In} 3 \mathrm{~d}$} & \multicolumn{2}{c}{$\mathrm{O} 1 \mathrm{~s}$} \\
\cline { 2 - 5 } & $\mathrm{In}^{3+}$ & $\mathrm{In}^{0}$ & $\mathrm{O}^{2-}$ & $\mathrm{OH}^{-}$ \\
\hline $\begin{array}{r}\text { Peak Binding } \\
\text { Energy (eV) }\end{array}$ & 444.8 & 443.7 & 530 & 532
\end{tabular}

Table 1. Binding peak energies for the main indium $3 d$ and oxygen 1 s species highlighted in the following discussions.

The $\mathrm{In}^{3+} / \mathrm{In}^{0}$ ratio for an $\mathrm{O}_{2}$ exposed indium surface shows significant increase after about $20 \mathrm{~L}$ of oxygen exposure to the substrate. This ratio quickly increases over the next 1,000 L of $\mathrm{O}_{2}$ exposure, plateauing at around 5,000 L. In contrast, $\operatorname{the}^{3+} \mathrm{In}^{3+} / \mathrm{In}^{0}$ ratio does not demonstrate significant oxidation until after $1000 \mathrm{~L}$ of $\mathrm{H}_{2} \mathrm{O}$ exposure, and begins to plateau at around $100,000 \mathrm{~L}$. 


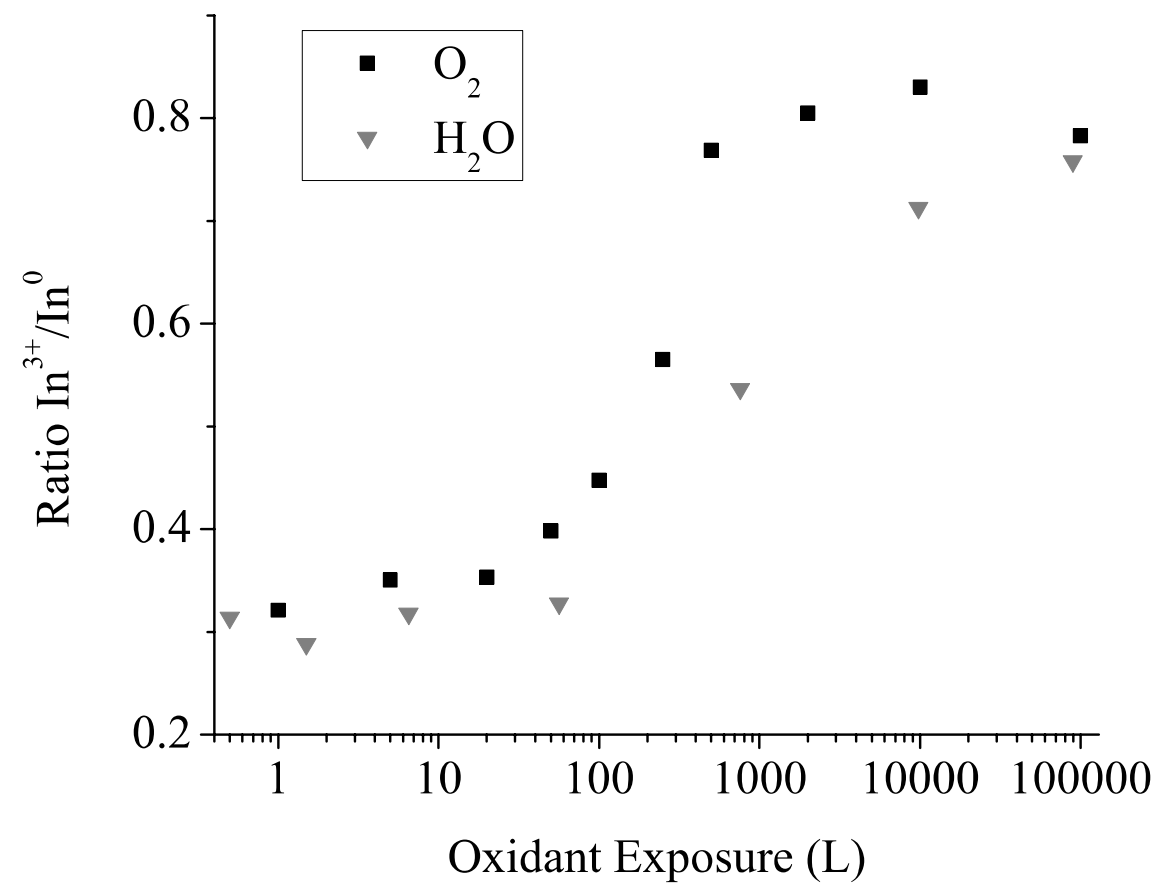

Figure 3. $\operatorname{In}^{3+}(444.8 \mathrm{eV}) / \mathrm{In}^{0}(443.7 \mathrm{eV})$ ratios plotted as a function of oxidant exposure by comparing the peak areas of the In $3 \mathrm{~d}_{5 / 2}$ peaks at each exposure point.

The most striking contrast between $\mathrm{O}_{2}$ and $\mathrm{H}_{2} \mathrm{O}$ oxidation of sputtered metallic indium foil in UHV is displayed in Figure 4. By taking the ratio of $\mathrm{O}^{2-} / \mathrm{OH}^{-}$and plotting it against exposure for each oxidant, it becomes clear that the indium surface terminates differently in each case. The $\mathrm{O}^{2-}$ signal in the case of $\mathrm{O}_{2}$ exposure is very large in the initial stages of oxidation and remains the dominant feature as exposure increases. The $\mathrm{O}^{2-} / \mathrm{OH}^{-}$ratio decreases logarithmically with $\mathrm{O}_{2}$ exposure. The $\mathrm{O}^{2-} / \mathrm{OH}^{-}$ratio for $\mathrm{H}_{2} \mathrm{O}$ oxidation of indium shows a much lower value at low water exposure values, and stays nearly constant until very high exposures. 


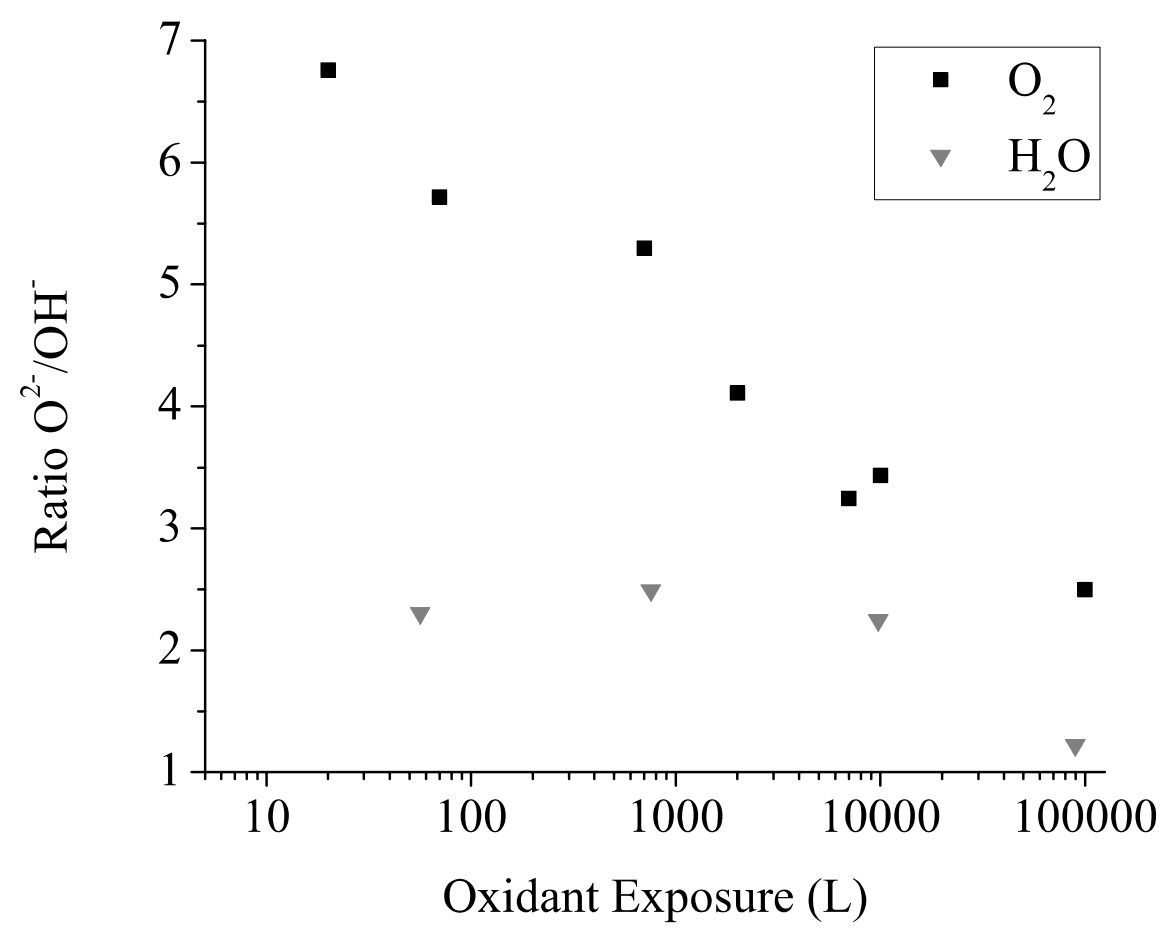

Figure 4. The ratio of the low binding energy $\mathrm{O} 1 \mathrm{~s}$ peak, associated with $\mathrm{O}^{2-}$, and the high binding energy $\mathrm{O}$ 1s peak, associated with $\mathrm{OH}^{-}$, plotted against the exposure of $\mathrm{O}_{2}$ (black squares) and $\mathrm{H}_{2} \mathrm{O}$ (gray triangles).

This data suggests that $\mathrm{O}_{2}$ is the better oxidant for indium and adsorbs dissociatively. Dissociation is likely driven by the oxidation of $\operatorname{In}^{0}$ to $\operatorname{In}^{3+}$, which starts to form an $\operatorname{In}_{2} \mathrm{O}_{3}$ layer. As more oxygen dissociatively adsorbs, $\mathrm{O}^{2-}$ is free to migrate to the oxide/metal interface growing a thin $\mathrm{In}_{2} \mathrm{O}_{3}$ film. As exposure increases, the $\mathrm{O}^{2-} / \mathrm{OH}^{-}$ratio decreases, suggesting that, slowly, due to trace $\mathrm{H}_{2} \mathrm{O}$ or $\mathrm{H}_{2}$ found in the chamber, $\mathrm{OH}^{-}$is beginning to significantly coat the oxide film by water adsorption, potentially dissociating directly at an $\mathrm{O}^{2-}$ site into two $\mathrm{OH}^{-}$in an acid-base equilibrium. The $\mathrm{O}^{2-} / \mathrm{OH}^{-}$ ratio continues to decrease as both $\mathrm{O}^{2-}$ migration into the metallic phase slows, and trace $\mathrm{H}_{2} \mathrm{O}$ and $\mathrm{H}_{2}$ increasingly impinge or react on the surface. 
Oxidation of In by $\mathrm{H}_{2} \mathrm{O}$ takes place by a significantly different mechanism than $\mathrm{O}_{2}$ oxidation, but yields a very similar oxide film. $\mathrm{H}_{2} \mathrm{O}$ first adsorbs dissociatively, making surface hydroxide and hydride. Bulk oxidation occurs as surface hydroxide loses a proton to recombine with hydride, producing $\mathrm{H}_{2}$, which desorbs, as observed and discussed in the TPD experiments below. The $\mathrm{O}^{2-}$ is then mobile enough to move to the $\operatorname{In}^{0}$ interface below the exposed surface, creating an $\operatorname{In}_{2} \mathrm{O}_{3}$ under layer between the hydroxylated surface and the metallic bulk. It appears that the rate of oxidation slows as this oxide film grows. In the case of $\mathrm{H}_{2} \mathrm{O}$ oxidation, the $\mathrm{O}^{2-} / \mathrm{OH}^{-}$ratio stays relatively constant as the oxidation occurs since there is an excess of $\mathrm{OH}^{-}$at the surface that is constantly being replenished by incident water. As the oxide layer reaches saturation thickness for the $P_{O_{2}}$ of the system, the $\mathrm{OH}^{-}$signal becomes more intense as the driving force for incorporation of $\mathrm{O}^{2-}$ into the substrate decreases. The growth of oxide in both the $\mathrm{H}_{2} \mathrm{O}$ and $\mathrm{O}_{2}$ environments is in accord with the growth of an n-type semiconducting oxide, which agrees with previous reports on $\operatorname{In}_{2} \mathrm{O}_{3}$.

As was observed by Rossnagel et. al., the present work does show slight oxidation of indium with $\mathrm{CO}_{2}$ exposures. However, the exposures were so high and took so long that it is likely that trace $\mathrm{O}_{2}$ and $\mathrm{H}_{2} \mathrm{O}$ in the system may have been responsible for the oxidation. ${ }^{12}$ The almost identical oxygen species observed for $\mathrm{CO}_{2}$ exposure as for oxygen and water exposure supports the oxidation via trace $\mathrm{O}_{2}$ and $\mathrm{H}_{2} \mathrm{O}$ contamination. Small carbonate or potentially formate species were observed in the C 1s region at $\sim 298$ $\mathrm{eV}$ in all samples after significant exposure. This suggests that the sequestration of carbon as a carbonate or formate species is favorable, but highly surface localized. Due to the weak carbon peak intensity and the observation of this peak in samples not exposed 
directly to $\mathrm{CO}_{2}$, it is difficult to confidently assign the origin of the carbon species as $\mathrm{CO}_{2}$ or trace $\mathrm{CO}$ in the system.

\section{Oxidation of Indium with $\mathrm{H}_{2} \mathrm{O}$ at Ambient Pressures}

After having demonstrated that a significant exposure of oxidant causes the indium surface to reach a relatively constant oxide/hydroxide speciation, a stronger correlation to atmospherically exposed samples was desired. In order to obtain this link, the speciation of indium foil and indium oxide was observed with XPS at relatively high $\mathrm{H}_{2} \mathrm{O}$ pressures. Figure 5a shows the In $3 \mathrm{~d}$ region of sputtered clean indium metal foil as acquired from a monochromatic x-ray source at the Lawrence Berkeley National Laboratory (LBNL) Advanced Light Source (ALS) Beamline 9.3.2 at $640 \mathrm{eV}$ beam energy. The metallic In $3 \mathrm{~d}_{5 / 2}$ peak at $443.7 \mathrm{eV}$ is the main species, with a small, oxidized In $3 \mathrm{~d}_{5 / 2}$ shoulder at a binding energy of $444.8 \mathrm{eV}$, in addition to corresponding $\operatorname{In} 3 \mathrm{~d}_{3 / 2}$ peaks and plasmons at higher binding energies. Figure $5 \mathrm{~b}$ shows the $\mathrm{Ar}^{+}$sputtered foil at an ambient $\boldsymbol{P}_{\boldsymbol{H}_{2} \boldsymbol{o}}$ of 50 mTorr. The $444.8 \mathrm{eV}$ peak becomes the dominant species under these conditions, and although the plasmon peak is no longer apparent, there is a distinct amount of metallic species still detectable. The In $3 \mathrm{~d}$ region of an $\operatorname{In}_{2} \mathrm{O}_{3}$ powder, seen in Figure 5c, did not change significantly between UHV and 50 mTorr $\boldsymbol{P}_{\boldsymbol{H}_{2} \boldsymbol{O}}$ conditions.

The ratio of $\mathrm{In}^{3+} / \mathrm{In}^{0}$ is 14.2 for the $\mathrm{H}_{2} \mathrm{O}$ exposed foil, which is much higher than the $\mathrm{In}^{3+} / \mathrm{In}^{0}$ ratio observed in either $\mathrm{O}_{2}$ or $\mathrm{H}_{2} \mathrm{O}$ exposures of $100,000 \mathrm{~L}$ carried out at $10^{-5}$ Torr. This indicates that the observed plateaus of the $\mathrm{In}^{3+} / \mathrm{In}^{0}$ ratio in the $\mathrm{O}_{2}$ and $\mathrm{H}_{2} \mathrm{O}$ exposures under UHV/HV conditions were due to the limited extent of indium oxidation at low oxidant pressures. 


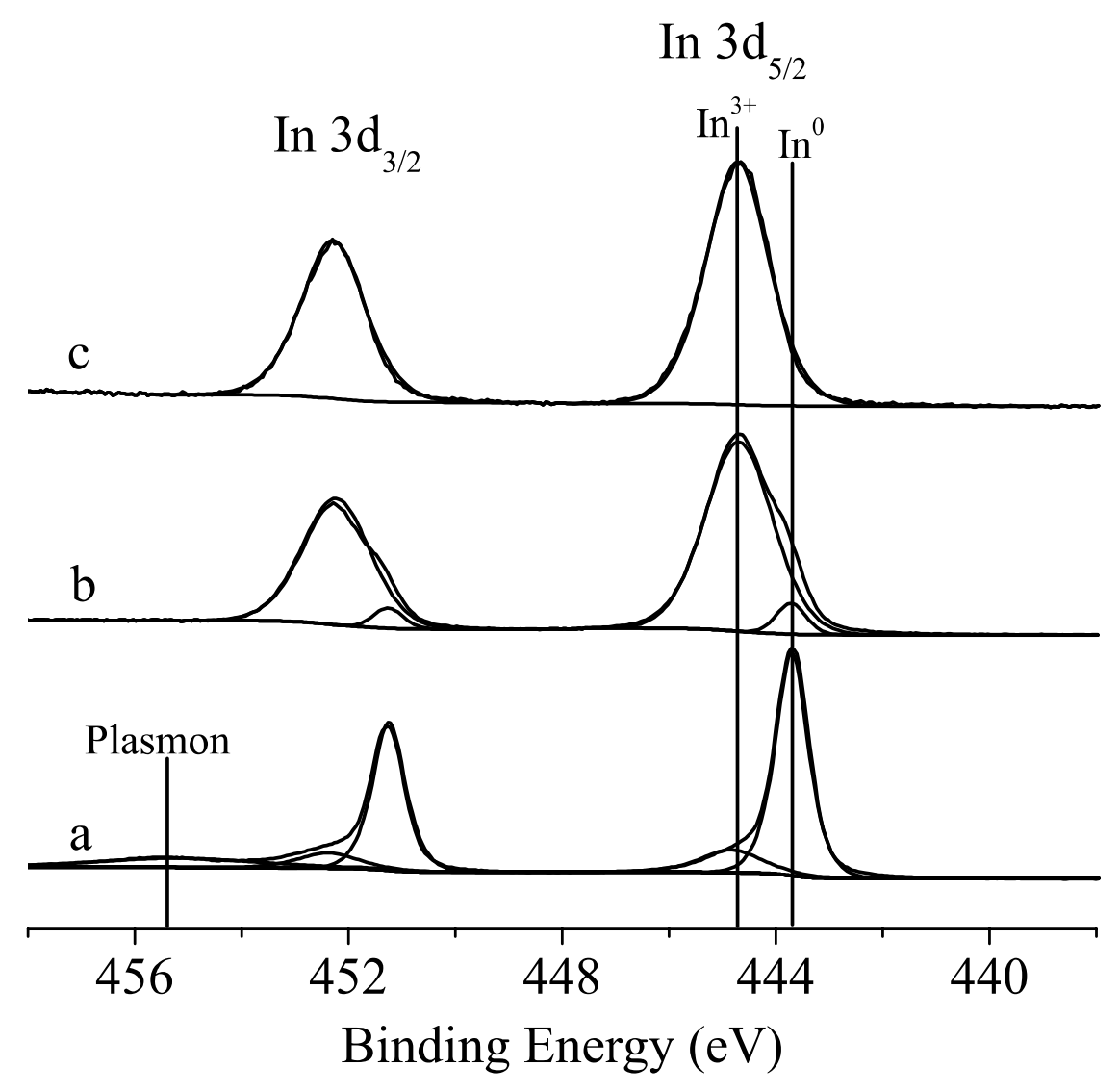

Figure 5. AP-XPS spectra in the In $3 d$ region for (a) $\mathrm{an} \mathrm{Ar}^{+}$sputtered indium foil in $\mathrm{UHV}$, (b) an $\mathrm{Ar}^{+}$sputtered indium foil while at a $\boldsymbol{P}_{\boldsymbol{H}_{2} \boldsymbol{O}}$ of 50 mTorr, and (c) $\mathrm{In}_{2} \mathrm{O}_{3}$ powder in UHV.

As with the previous $\mathrm{O}_{2}$ and $\mathrm{H}_{2} \mathrm{O}$ exposures, more detail about surface speciation can be gleaned from the $\mathrm{O} 1 \mathrm{~s}$ region of the spectrum. Figure 6a shows the $\mathrm{O} 1 \mathrm{~s}$ region of the $\mathrm{Ar}^{+}$sputtered indium foil, where there are small peaks that can be assigned to the $\mathrm{O}^{2-}$ and $\mathrm{OH}^{-}$species. When the $P_{\mathrm{H}_{2} \mathrm{O}}$ in the chamber is raised to 50 mTorr, both oxygen peaks increase in intensity dramatically, as seen in Figure $6 \mathrm{~b}$, in unison with the $\mathrm{In}^{3+}$ peak seen Figure 5b. The $\mathrm{O}^{2-} / \mathrm{OH}^{-}$ratio at 50 mTorr pressure of $\mathrm{H}_{2} \mathrm{O}$ is 0.80 , lower than previously observed in the UHV/HV exposures. Interestingly, as shown in Figure 6c, the 
$\mathrm{O}^{2-} / \mathrm{OH}^{-}$ratio increases on evacuation of the $\mathrm{H}_{2} \mathrm{O}$ to 0.82 . This shows that the $\mathrm{O}^{2-} / \mathrm{OH}^{-}$ ratio is dependent on the $P_{\mathrm{H}_{2} \mathrm{O}}$ in the system, indicating that an equilibrium exists between the oxidized indium layer and $\mathrm{H}_{2} \mathrm{O}_{(\mathrm{g})}$.

Figure $6 \mathrm{~d}$ shows the $\mathrm{O} 1 \mathrm{~s}$ region of an $\mathrm{In}_{2} \mathrm{O}_{3}$ powder, corresponding to the In $3 \mathrm{~d}$ region shown in Figure 5c. Both $\mathrm{O}$ 1s species are present with an $\mathrm{O}^{2-} / \mathrm{OH}^{-}$ratio of 1.32. Again, at a $P_{\mathrm{H}_{2} \mathrm{O}}$ of $50 \mathrm{mTorr}$, the $\mathrm{O}^{2-} / \mathrm{OH}^{-}$ratio drops significantly to 0.74 as seen in Figure 6e. The highest binding energy peak seen in Figure $6 \mathrm{~b}$ at $536 \mathrm{eV}$, and Figure 6e at $535 \mathrm{eV}$ is due to water in the vapor phase. It does not fall at the same binding energy in the two experiments because the sample of $\operatorname{In}_{2} \mathrm{O}_{3}$ charged significantly under the intense light source, and had to be calibrated according to the $\mathrm{C} 1 \mathrm{~s}$ region. In both of these cases

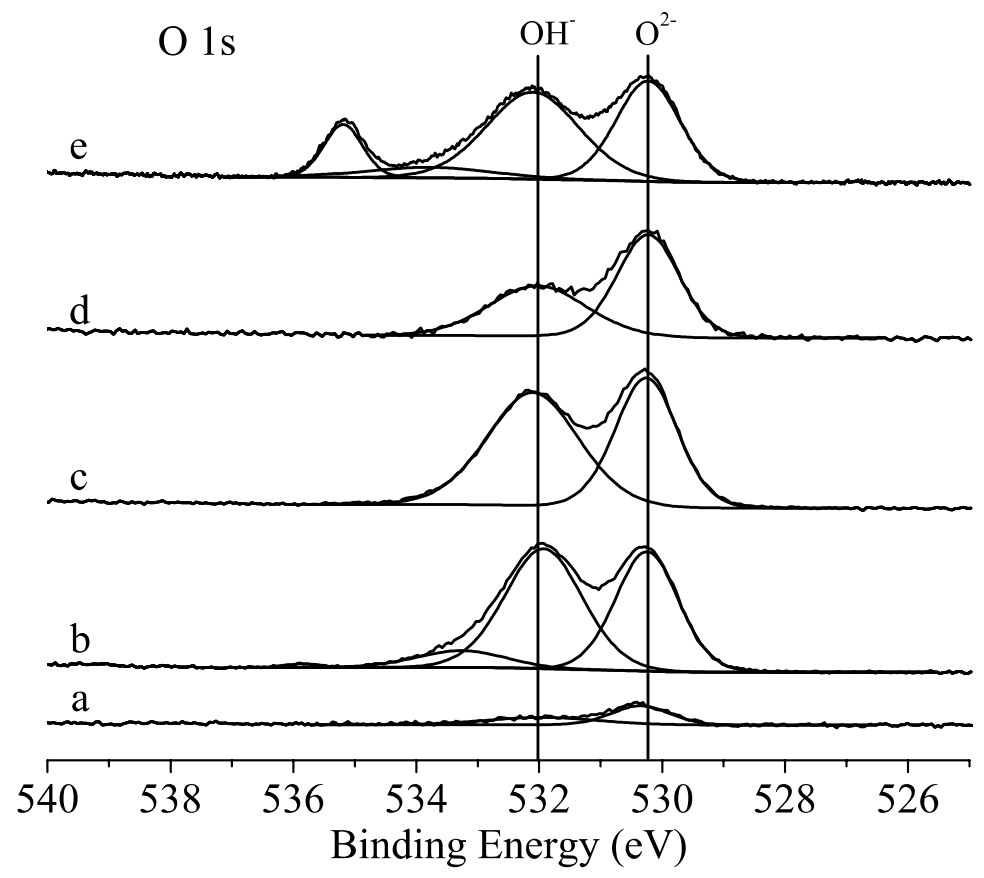

Figure 6. AP-XPS spectra in the $\mathrm{O}$ 1s region for (a) an $\mathrm{Ar}^{+}$sputtered indium foil in UHV, (b) an $\mathrm{Ar}^{+}$sputtered indium foil while at a $\boldsymbol{P}_{\boldsymbol{H}_{2} \boldsymbol{O}}$ of $50 \mathrm{mTorr}$, (c) the foil after exposure at a $\boldsymbol{P}_{\boldsymbol{H}_{2} \boldsymbol{O}}$ of 50 mTorr after pumping back down to UHV pressure, (d) $\mathrm{In}_{2} \mathrm{O}_{3}$ powder in UHV and (e) while at a $\boldsymbol{P}_{\boldsymbol{H}_{2} \boldsymbol{O}}$ of 50 mTorr. 
there is also a peak around $533.5 \mathrm{eV}$ that can be attributed to physisorbed $\mathrm{H}_{2} \mathrm{O}$.

These combined UHV and ambient pressure XPS data demonstrate that the order and extent of indium oxidation is dictated by the distribution and pressure of oxidants present in the oxidizing atmosphere. The terminal hydroxylation of the indium substrate appears to depend on the level of water in this oxidizing atmosphere.

\section{HREELS at Metallic Indium and Oxidized Indium with $\mathrm{H}_{2} \mathrm{O}$ Exposure}

In order to probe the mechanism of adsorption and the potential implications on oxide growth and stability, HREELS was performed under UHV conditions to study the initial steps of metallic oxidation with $\mathrm{O}_{2}$ and $\mathrm{H}_{2} \mathrm{O}$. HREELS spectra were obtained from an $\mathrm{Ar}^{+}$sputtered indium metal foil at 135K, and are shown in Figure 7a. Only after exposing to $40 \mathrm{~L}$ of $\mathrm{H}_{2} \mathrm{O}$ were any $\mathrm{H}_{2} \mathrm{O}$ vibrational modes observed. These modes were seen at $720 \mathrm{~cm}^{-1}, 1640 \mathrm{~cm}^{-1}$, and $3660 \mathrm{~cm}^{-1}$, which correspond to a frustrated rotation mode, a scissoring mode, and an $\mathrm{O}-\mathrm{H}$ stretching mode of $\mathrm{H}_{2} \mathrm{O}$, respectively. ${ }^{20}$ In addition to the $\mathrm{H}_{2} \mathrm{O}$ vibrational modes, there also appears to be a mode at $450 \mathrm{~cm}^{-1}$. This mode is likely an In-O mode of In hydroxide, as seen in previous work. ${ }^{21}$ Additionally there are small hydrocarbon contamination modes seen at $1450 \mathrm{~cm}^{-1}$ and $2920 \mathrm{~cm}^{-1}$. Exposing this surface to another $60 \mathrm{~L}$ of $\mathrm{H}_{2} \mathrm{O}$, (total of $100 \mathrm{~L}$ ) shows an increase in the water modes and the In-O mode, indicating both water ice and In hydroxide formation on the surface. If the sample is then annealed to $350 \mathrm{~K}\left(77^{\circ} \mathrm{C}\right)$, the vibrational spectrum changes significantly, displaying a large peak at $530 \mathrm{~cm}^{-1}$ and a small $\mathrm{OH}$ stretch at $3620 \mathrm{~cm}^{-1}$. The large peak around $530 \mathrm{~cm}^{-1}$ is most likely due to the formation of In oxide, and the small $\mathrm{OH}$ peak around $3600 \mathrm{~cm}^{-1}$ is due to small amounts of surface hydroxide formation 
by residual $\mathrm{H}_{2} \mathrm{O}$. Additionally, after annealing there is no detectable signal from molecular water vibrational modes.

The differences between water adsorption on indium oxide and metallic indium were observed by pre-oxidizing the metallic indium surface with oxygen and subsequently exposing water. Figure $7 \mathrm{~b}$ shows the $\mathrm{Ar}^{+}$sputtered surface after exposure to $50 \mathrm{~L}$ of $\mathrm{O}_{2}$ at room temperature. The metal oxide mode seen after annealing the $\mathrm{H}_{2} \mathrm{O}$ exposed metallic sample is seen again at $530 \mathrm{~cm}^{-1}$. After exposing to a total of $2000 \mathrm{~L}$ of $\mathrm{O}_{2}$, there is a very large peak at $560 \mathrm{~cm}^{-1}$, and significant $\mathrm{OH}$ stretch mode $3610 \mathrm{~cm}^{-1}$. There is, once again, hydrocarbon contamination present at 1450 and $2940 \mathrm{~cm}^{-1}$. After collecting the $2000 \mathrm{~L} \mathrm{O}_{2}$ exposed HREELS spectrum, the sample was cooled to $135 \mathrm{~K}$ and then exposed to $10 \mathrm{~L}$ of $\mathrm{H}_{2} \mathrm{O}$. In this spectrum there were very strong $\mathrm{H}_{2} \mathrm{O}$ vibrational modes observed at $1620 \mathrm{~cm}^{-1}$ and at $3580 \mathrm{~cm}^{-1}$. Low energy water modes are obscured by a strong $560 \mathrm{~cm}^{-1}$ signal. This difference in $\mathrm{OH}$ stretch and bend frequency indicates formation of a more ordered ice film at the oxidized indium surface than at the metallic surface, perhaps due to the improved wetting of $\mathrm{H}_{2} \mathrm{O}$ on the oxide surface compared to the metallic surface. Signal strength may also imply that there is more $\mathrm{H}_{2} \mathrm{O}$ adsorbed on the oxide surface after $10 \mathrm{~L}_{\text {of }} \mathrm{H}_{2} \mathrm{O}$ exposure than adsorbed to the metallic surface after $100 \mathrm{~L}$ of $\mathrm{H}_{2} \mathrm{O}$ exposure. This could be explained by the formation of In hydroxide during the $100 \mathrm{~L} \mathrm{H}_{2} \mathrm{O}$ exposure. 

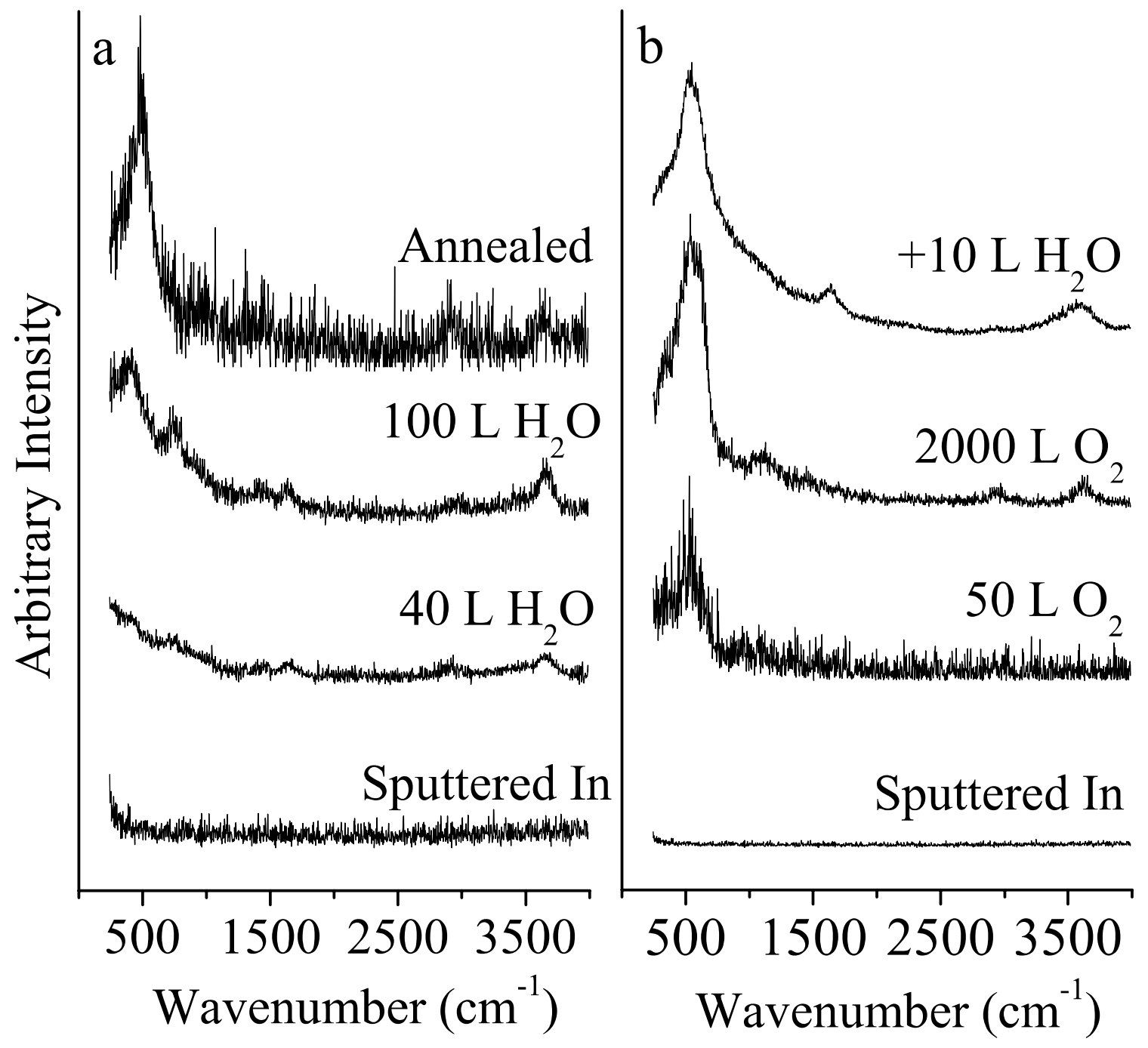

Figure 7. HREELS spectra of (a) an $\mathrm{Ar}^{+}$sputtered metallic indium foil at $\sim 135 \mathrm{~K}$ exposed to $40 \mathrm{~L}$ and $100 \mathrm{~L}$ of $\mathrm{H}_{2} \mathrm{O}$ before annealing to $350 \mathrm{~K}$, and (b) an $\mathrm{Ar}^{+}$sputtered

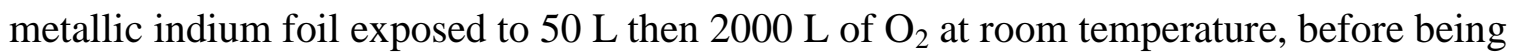
cooled to $\sim 135 \mathrm{~K}$ and then exposed to $10 \mathrm{~L}$ of $\mathrm{H}_{2} \mathrm{O}$.

The HREELS data strongly indicate that even at low temperatures, $\mathrm{H}_{2} \mathrm{O}$ can dissociatively adsorb, but the formation of indium oxide is suppressed until higher temperatures. This may be due to the barrier to $\mathrm{O}^{2-}$ diffusion to the metallic interface through a growing oxide lattice thin film. From XPS and HREELS data, an indium 
surface appears to oxidize through the dissociative adsorption of $\mathrm{O}_{2}$ or $\mathrm{H}_{2} \mathrm{O}$, followed by the diffusion of $\mathrm{O}^{2-}$ to the metal/oxide interface, forming a subsurface oxide film. The depth of this oxide and the speciation of the exposed surface is governed by the adjacent atmosphere composition.

\section{TPD from Metallic Indium and Oxidized Indium in UHV After $\mathrm{H}_{2} \mathrm{O}$ Exposure}

In order to further understand how $\mathrm{H}_{2} \mathrm{O}$ adsorbs on indium metal and indium oxide differently and to observe what reaction products are present, water was exposed to the two substrates independently and then temperature programmed desorption spectra were obtained for varying surface exposures.

Figure 8a demonstrates the desorption spectra following the exposure of $0.5 \mathrm{~L}, 1$ $\mathrm{L}, 2 \mathrm{~L}$, and $10 \mathrm{~L}$ of $\mathrm{H}_{2} \mathrm{O}$ to an $\mathrm{Ar}^{+}$sputtered indium surface. At $0.5 \mathrm{~L}$ of exposure, there are two distinct peaks at $158 \mathrm{~K}$ and $169 \mathrm{~K}$, with a broad feature centered around $197 \mathrm{~K}$. The TPD spectrum for $1 \mathrm{~L}$ of $\mathrm{H}_{2} \mathrm{O}$ exposure shows similar peaks, but the peak positions shift to higher temperatures, $164 \mathrm{~K}, 176 \mathrm{~K}$, and $212 \mathrm{~K}$, respectively. $\mathrm{H}_{2} \mathrm{O}$ exposure of 2 L shifts the peaks to even higher temperatures, $166 \mathrm{~K}, 181 \mathrm{~K}$, and $216 \mathrm{~K}$, respectively. Lastly, at $10 \mathrm{~L}$ of $\mathrm{H}_{2} \mathrm{O}$ exposure on metallic indium, the desorption peaks shift to temperatures of $173 \mathrm{~K}, 191 \mathrm{~K}$, and $230 \mathrm{~K}$, respectively, with the broad peak at around $230 \mathrm{~K}$ distinctly displaying multiple features.

Figure $8 \mathrm{~b}$ shows the TPD spectra for the same $\mathrm{H}_{2} \mathrm{O}$ exposures on an $\mathrm{Ar}^{+}$sputtered indium metal substrate that was exposed to $\sim 2000 \mathrm{~L}_{\text {of }} \mathrm{O}_{2}$ at room temperature to generate an oxidized surface. The $0.5 \mathrm{~L} \mathrm{H}_{2} \mathrm{O}$ exposure shows a distinctly different shape for the oxidized species, with two overlapping peaks. The primary peak is found at $163 \mathrm{~K}$, with the shoulder centered at approximately $169 \mathrm{~K}$, and a broad feature centered around 
$200 \mathrm{~K}$. At $1 \mathrm{~L} \mathrm{H}_{2} \mathrm{O}$ exposure the primary peak area increases, but is centered at the same temperature as $0.5 \mathrm{~L} \mathrm{H}_{2} \mathrm{O}$ exposure: $163 \mathrm{~K}$. The shoulder peak shifts to $\sim 172 \mathrm{~K}$, and the broad feature shifts to $208 \mathrm{~K}$. After $2 \mathrm{~L} \mathrm{H}_{2} \mathrm{O}$ exposure the primary peak is still found at $163 \mathrm{~K}$, with the shoulder shifted to $\sim 175 \mathrm{~K}$. The broad feature also appears to shift to higher temperature. Upon exposure to $10 \mathrm{~L}$ of $\mathrm{H}_{2} \mathrm{O}$, the primary peak shifts substantially to $171 \mathrm{~K}$. The shoulder distinctly separates with a peak at $190 \mathrm{~K}$, and the broad feature, similar to $10 \mathrm{~L} \mathrm{H}_{2} \mathrm{O}$ exposure on clean metallic indium, shows multiple desorption peaks centered at $233 \mathrm{~K}$.

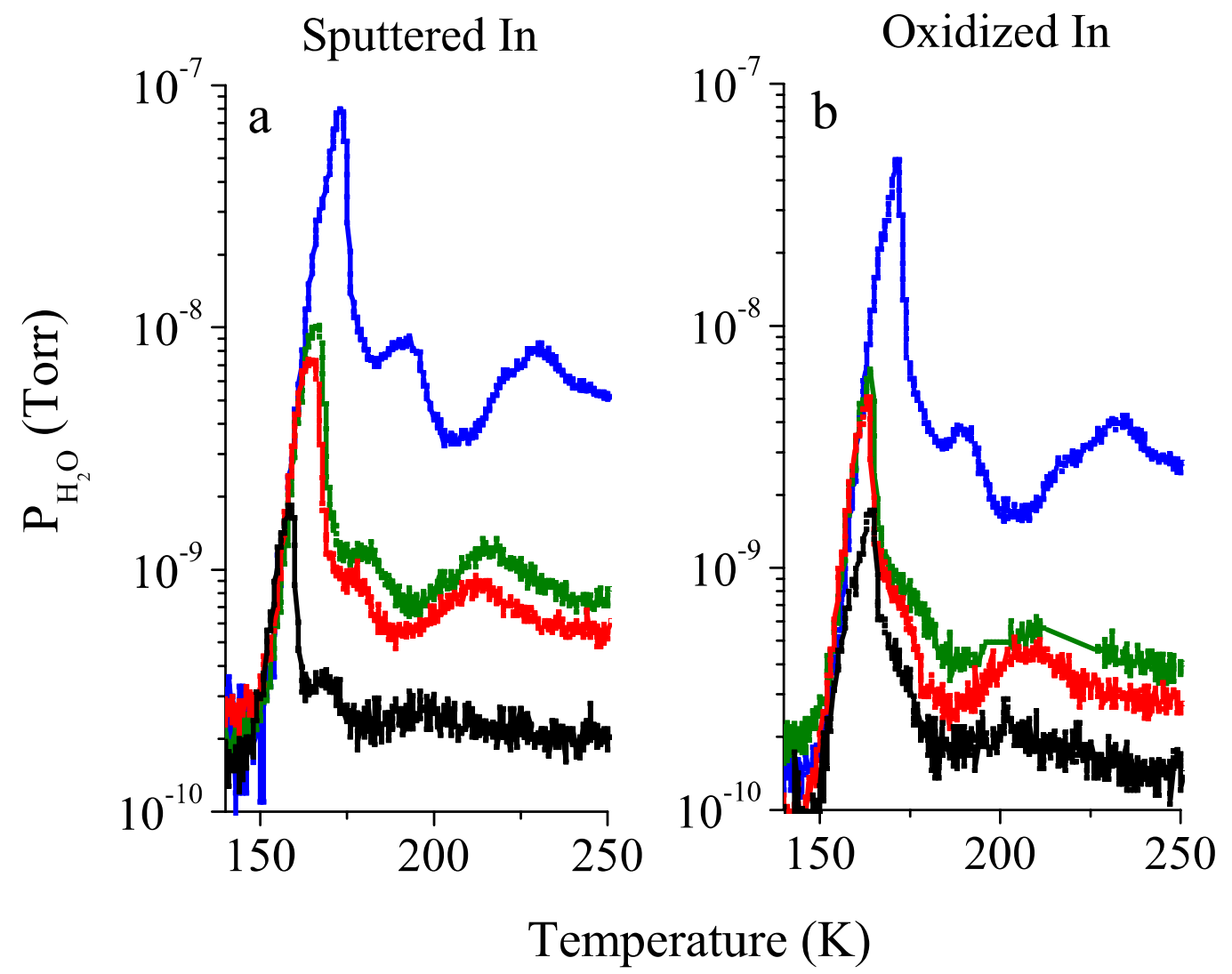

Figure 8. TPD spectra on a logarithmic pressure scale of (a) sputtered indium and (b) indium exposed to 2,000 $\mathrm{L}$ of $\mathrm{O}_{2}$ at room temperature, each after being exposed to (black) $0.5 \mathrm{~L}$, (red) $1 \mathrm{~L}$, (green) $2 \mathrm{~L}$, and (blue) $10 \mathrm{~L}$ of $\mathrm{H}_{2} \mathrm{O}$ at $\sim 135 \mathrm{~K}$. 
Figure 9 shows the TPD for the low $\mathrm{H}_{2} \mathrm{O}$ exposures from Figure 8 on a linear scale instead of a logarithmic scale. Here the increase in peak area is more pronounced and the peak position shifts are emphasized. The behavior of the primary peak in Figure 9a is indicative of a zeroth order process, which is typical of molecular water adsorption to form ice. This indicates that the adsorbed water at this temperature is more strongly interacting with itself than with the metallic substrate. ${ }^{22}$ The dramatic change in peak shape and position to higher temperatures in the primary peak for the oxidized indium, seen in Figure 9b, is indicative of a change in desorption to first order. ${ }^{23}$ The higher desorption temperature observed for low $\mathrm{H}_{2} \mathrm{O}$ exposure indicates greater adsorption strength between $\mathrm{H}_{2} \mathrm{O}$ and the oxidized substrate than between $\mathrm{H}_{2} \mathrm{O}$ and the metallic substrate. The change to first order reaction is indicative of a non-dissociative adsorption of $\mathrm{H}_{2} \mathrm{O}$ on the oxidized substrate. ${ }^{24}$

In addition to monitoring $\mathrm{H}_{2} \mathrm{O}(18 \mathrm{M} / \mathrm{Z})$ during programmed desorption, $\mathrm{O}_{2}$ (32 $\mathrm{M} / \mathrm{Z}), \mathrm{H}_{2}(2 \mathrm{M} / \mathrm{Z}), \mathrm{N}_{2}(28$ and $14 \mathrm{M} / \mathrm{Z}), \mathrm{CO}(28$ and $12 \mathrm{M} / \mathrm{Z})$ and $\operatorname{Ar}(40 \mathrm{M} / \mathrm{Z})$ were also recorded. Of these, only $\mathrm{H}_{2}$ showed significant desorption over the observed temperature range. The single $\mathrm{H}_{2}$ peak corresponded closely to desorption of the primary $\mathrm{H}_{2} \mathrm{O}$ peak for both metallic indium and oxidized indium, and sat on a higher baseline than the other monitored gases. Overlaid $\mathrm{H}_{2}$ and $\mathrm{H}_{2} \mathrm{O}$ TPD spectra for $1 \mathrm{~L}$ of $\mathrm{H}_{2} \mathrm{O}$ exposure on metallic indium, Figure 10a, and oxidized indium, Figure 10b, show similar relative $\mathrm{H}_{2} / \mathrm{H}_{2} \mathrm{O}$ peak ratios. Interestingly, the $\mathrm{H}_{2}$ peak and $\mathrm{H}_{2} \mathrm{O}$ peak from the oxidized indium sample appear at the same temperature, $163 \mathrm{~K}$. This is not the case for $\mathrm{H}_{2}$ and $\mathrm{H}_{2} \mathrm{O}$ desorption from metallic indium, where $\mathrm{H}_{2} \mathrm{O}$ peaks at $164 \mathrm{~K}$, while $\mathrm{H}_{2}$ peaks slightly later, at $166 \mathrm{~K}$, which corresponds to a delay of $\sim 15$ seconds at this heating rate. This offset in $\mathrm{H}_{2}$ peak 
from the $\mathrm{H}_{2} \mathrm{O}$ primary peak is observed at $2 \mathrm{~L} \mathrm{H}_{2} \mathrm{O}$ exposure to metallic indium as well, while $\mathrm{H}_{2}$ and $\mathrm{H}_{2} \mathrm{O}$ peaks for the $2 \mathrm{~L}_{2} \mathrm{O}$ exposure on oxidized indium again demonstrate coincidence.

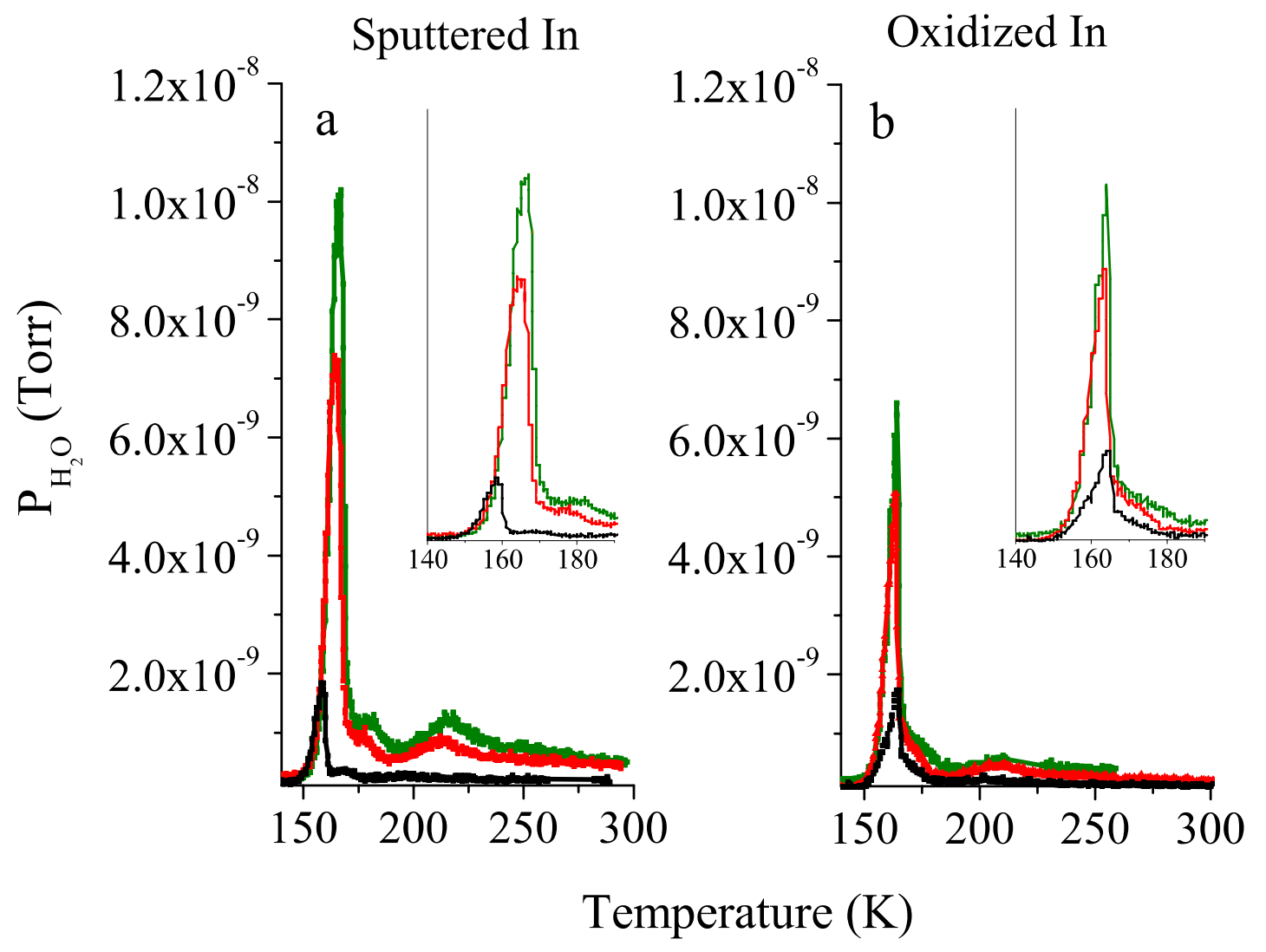

Figure 9. TPD spectra on a linear pressure scale of (a) sputtered indium and (b) indium exposed to 2,000 $\mathrm{L}$ of $\mathrm{O}_{2}$ at room temperature, each after being exposed to (black) $0.5 \mathrm{~L}$, (red) $1 \mathrm{~L}$, and (green) $2 \mathrm{~L}$ of $\mathrm{H}_{2} \mathrm{O}$ at $\sim 135 \mathrm{~K}$. The inset for each spectrum shows the primary peak region in greater detail.

The TPD spectra suggest that $\mathrm{H}_{2} \mathrm{O}$ adsorbs more strongly on the oxidized surface, where the adsorption of $\mathrm{H}_{2} \mathrm{O}$ to the metal surface at these temperatures is a weaker interaction. Further, the metallic indium demonstrates a slightly higher temperature release of $\mathrm{H}_{2}$, suggesting that as the substrate desorbs water, at some small coverage, the 
metallic substrate is oxidized. This is supported by the change in HREELS spectrum after annealing the substrate above the desorption peak temperature, as seen in Figure 7, showing the presence of metal-oxide after water is desorbed.

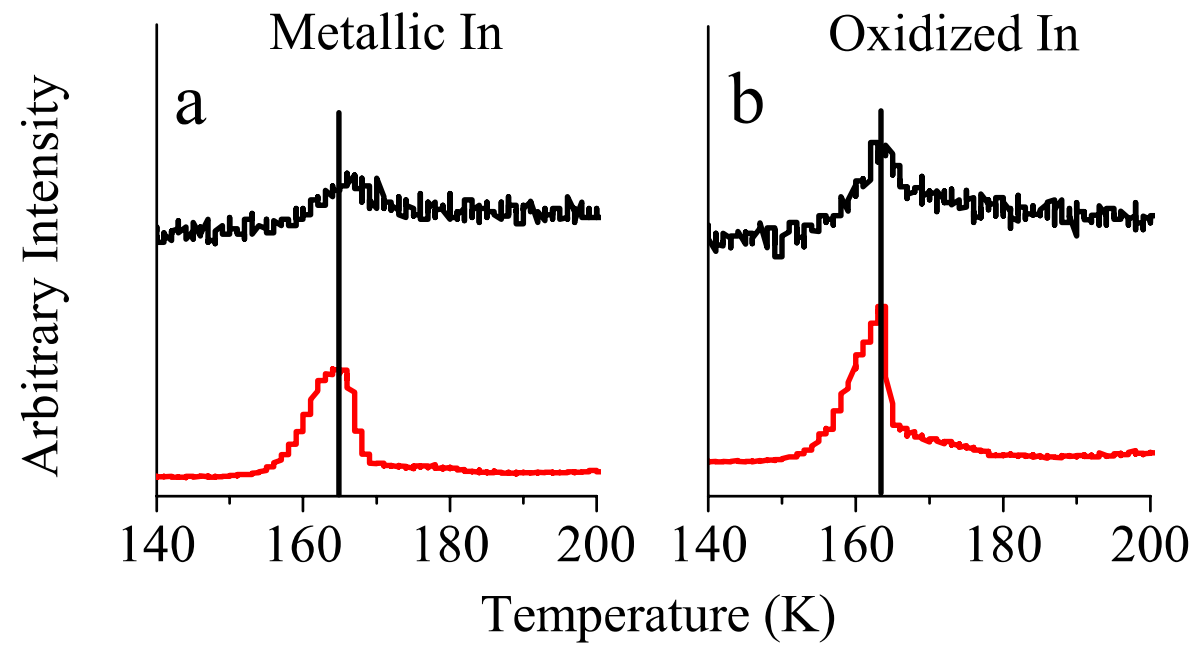

Figure 10. TPD spectra on a linear pressure scale of (red) $\mathrm{H}_{2} \mathrm{O}$ and (black) $\mathrm{H}_{2}$ desorption from (a) $\mathrm{Ar}^{+}$sputtered metallic indium, and (b) $2000 \mathrm{~L} \mathrm{O}_{2}$ oxidized indium.

\section{Conclusions}

From the data discussed above, it is evident that the major species exposed at a native indium metal surface under atmospheric conditions is a hydroxide species. $\mathrm{O}_{2}$ and $\mathrm{H}_{2} \mathrm{O}$ exposure demonstrates that after or during terminal hydroxylation, an $\mathrm{In}_{2} \mathrm{O}_{3}$ layer is formed. The hydroxyl termination of this native oxide is also observed in pure $\operatorname{In}_{2} \mathrm{O}_{3}$ samples, attesting to the basicity of the metal oxide, which forms $\mathrm{OH}$ groups from oxide and $\mathrm{H}_{2} \mathrm{O}$. There is a strong possibility that the equilibrium that favors hydroxyl formation at high $\mathrm{H}_{2} \mathrm{O}$ pressures acts to passivate the metal from further oxidation in a manner similar to other group XIII elements. ${ }^{25}$ The data demonstrate how a humid atmosphere can directly affect the order of oxidation and the potential for processing conditions to significantly impact the conductivity of the final oxide due to incorporation 
of hydroxide doping. This understanding is useful for the development of further indiumderived products. This work also has potential implications for the mechanistic pathways of indium surface catalyzed reactions currently being performed in various settings. It is thus important that the active environment be considered in indium catalysis and indium materials synthesis, since the surface speciation is a sensitive function of the composition of the oxidizing atmosphere.

\section{Acknowledgements}

This work was partially supported by the US National Science Foundation, Division of Chemistry, CHE-1213216. Support of an Advanced Light Source user proposal beam time request is also acknowledged.

\section{References}

1. Chemistry of Aluminium, Gallium, Indium, and Thallium. Blackie Academic \& Professional: London, 1993.

2. Bennet, G. D. a. P., L. A., Allylindation In Aqueous Media: Methyl 3(Hydroxymethyl)-4-Methyl-2-methylenepentanoate. Organic Sytheses 2000, 77, 107. 3. Wildermann, A.; Foricher, Y.; Netscher, T.; Bonrath, W., New application of indium catalysts: A novel and green concept in the fine chemicals industry. In Pure and Applied Chemistry, 2007; Vol. 79, p 1839.

4. $\quad$ Purvis, K. L.; Lu, G.; Schwartz, J.; Bernasek, S. L., Surface Characterization and Modification of Indium Tin Oxide in Ultrahigh Vacuum. Journal of the American Chemical Society 2000, 122 (8), 1808-1809.

5. Ueda, Y.; Abe, J.; Murata, H.; Gotoh, Y.; Sakai, O., Control of work function of indium tin oxide: A surface treatment by atmospheric-pressure plasma layer on fabrictype electrodes. Japanese Journal of Applied Physics 2014, 53 (3S2), 03 DG03.

6. Schlaf, R.; Murata, H.; Kafafi, Z. H., Work function measurements on indium tin oxide films. Journal of Electron Spectroscopy and Related Phenomena 2001, 120 (1-3), 149-154.

7. T. Krishnakumar, R. J., V.N. Singh, ; B.R. Mehta, A. R. P., Synthesis and characterization of tin oxide nanoparticle for humidity sensor applications. Journal of Nano Research 2008, 4, 91-101.

8. Detweiler, Z. M.; White, J. L.; Bernasek, S. L.; Bocarsly, A. B., Anodized Indium Metal Electrodes for Enhanced Carbon Dioxide Reduction in Aqueous Electrolyte.

Langmuir 2014, 30 (25), 7593-7600. 
9. Splinter, S. J.; McIntyre, N. S.; Lennard, W. N.; Griffiths, K.; Palumbo, G., An AES and XPS study of the initial oxidation of polycrystalline magnesium with water vapour at room temperature. Surface Science 1993, 292 (1, Ä̀i2), 130-144.

10. Grosvenor, A. P.; Kobe, B. A.; McIntyre, N. S., Examination of the oxidation of iron by oxygen using X-ray photoelectron spectroscopy and QUASESTM. Surface Science 2004, 565 (2-3), 151-162.

11. Lin, A. W. C.; Armstrong, N. R.; Kuwana, T., X-ray photoelectron/Auger electron spectroscopic studies of tin and indium metal foils and oxides. Analytical Chemistry 1977, 49 (8), 1228-1235.

12. Rossnagel, S. M.; Dylla, H. F.; Cohen, S. A., AES study of the adsorption of $\mathrm{O}_{2}$, $\mathrm{CO}, \mathrm{CO}_{2}$, and $\mathrm{H}_{2} \mathrm{O}$ on indium. Journal of Vacuum Science and Technology 1979, 16 (2), 558-561.

13. Hewitt, R. W.; Winograd, N., Oxidation of polycrystalline indium studied by xray photoelectron spectroscopy and static secondary ion mass spectroscopy. J. Appl. Phys. 1980, 51, 2620-2624.

14. Sen, P.; Hegde, M. S.; Rao, C. N. R., Surface oxidation of cadmium, indium, tin and antimony by photoelectron and Auger spectroscopy. Applications of Surface Science 1982, $10(1), 63-74$.

15. Jeong, J. I.; Moon, J. H.; Hong, J. H.; Kang, J. Ä.; Fukuda, Y.; Lee, Y. P., Characterization of low-resistivity indium oxide films by Auger electron spectroscopy, $\mathrm{x}-$ ray photoelectron spectroscopy, and x-ray diffraction and correlation between their properties, composition, and texture. Journal of Vacuum Science \&amp; Technology A 1996, 14 (2), 293-298.

16. Dupin, J.-C.; Gonbeau, D.; Vinatier, P.; Levasseur, A., Systematic XPS studies of metal oxides, hydroxides and peroxides. Physical Chemistry Chemical Physics 2000, 2 (6), 1319-1324.

17. Kleber, S., Graham, M. J., Moisa, S., Sproule, G. I., Wu, X., Landheer, D., SpringThorpe, A. J., Barrios, P. J., Schmuki, P., Composition and Growth of Thermal and Anodic Oxides on InAlP. In Passivation of Metals and Semiconductors, and Properties of Thin Oxide Layers: a selection of papers from the 9th international symposium, Paris, France, 27 June-July 2005, Marcus, P., Maurice, V., Ed. Elsevier B. V.: Amsterdam, 2006; pp 263-270.

18. Li, C.; Lian, S.; Liu, Y.; Liu, S.; Kang, Z., Preparation and photoluminescence study of mesoporous indium hydroxide nanorods. Materials Research Bulletin 2010, 45 (2), 109-112.

19. Faur, M.; Faur, M.; Jayne, D. T.; Goradia, M.; Goradia, C., XPS investigation of anodic oxides grown on p-type InP. Surface and Interface Analysis 1990, 15 (11), 641650 .

20. Chakarov, D. V.; Österlund, L.; Kasemo, B., Water adsorption on graphite (0001). Vacuum 1995, 46 (8-10), 1109-1112.

21. Yan, T.; Long, J.; Chen, Y.; Wang, X.; Li, D.; Fu, X., Indium hydroxide: A highly active and low deactivated catalyst for photoinduced oxidation of benzene. Comptes Rendus Chimie 2008, 11 (1-2), 101-106.

22. Rudzinski, W., Steele, W. A., Zgrablich, G., Equilibria and Dynamics of Gas Adsorption on Heterogeneous Solid Surfaces. Elsevier: 1997. 
23. Niemantsverdriet, J. W.; Markert, K.; Wandelt, K., The compensation effect and the manifestation of lateral interactions in thermal desorption spectroscopy. Applied Surface Science 1988, 31 (2), 211-219.

24. Kolasinski, K. W., Surface Science: Foundations of Catalysis and Nanoscience. 3rd ed.; Wiley: 2012.

25. van den Brand, J.; Snijders, P. C.; Sloof, W. G.; Terryn, H.; de Wit, J. H. W., Acid-Base Characterization of Aluminum Oxide Surfaces with XPS. The Journal of Physical Chemistry B 2004, 108 (19), 6017-6024. 

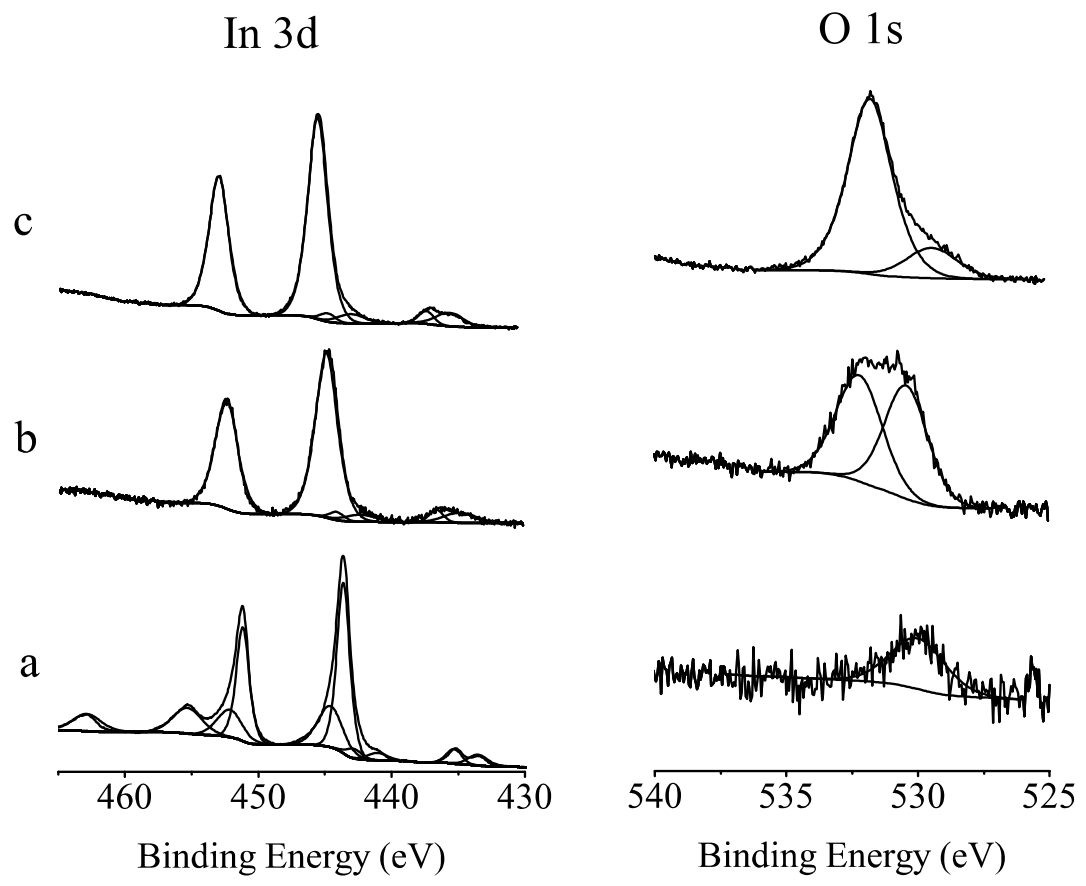

Graphical Abstract 